\title{
Pre-service Elementary Teachers' Reasoning Types of Generalization and Justification on a Figural Pattern Task
}

\begin{tabular}{ll} 
& Sumeyra Dogan Coskun* \\
\multicolumn{1}{c}{ Department of Elementary and Early Childhood Education, Faculty of Education, } \\
Eskisehir Osmangazi University, Eskisehir, Turkey \\
ORCID: 0000-0001-9401-6561
\end{tabular}

\section{Introduction}

Generalization, a cornerstone of algebra, is accepted as vital for mathematics and mathematical thinking (Kaput, 1999; Lee, 1996; Mason, 1996). Specifically, Lee (1996) states "algebra, and indeed all of mathematics is about generalizing patterns" (p. 103). Because of its importance, the National Council of Teachers of Mathematics [NCTM] started to incorporate algebra into the elementary mathematics curriculum (Kilpatrick \& Izsák, 2008). Furthermore, researchers explain that generalization can be used to help students connect arithmetic and 
algebra (Kaput, 1999; Mason, 1996). If this connection cannot be established, then students would have difficulties in algebra (Kaput, 1999; Warren, 2005). To overcome possible difficulties, and even to prevent them from occurring, teachers need to have the necessary understanding of the related concepts. In this context, this study examines pre-service elementary teachers' understanding of pattern generalization by identifying their strategies and reasoning types. This study also describes the pre-service elementary teachers' subsequent reasoning types for justification as justification and generalization are inseparable twins (Lannin, 2005).

\section{Theoretical Background}

\section{Generalization and Justification}

Generalization is defined in different ways by several researchers. Specifically, Harel and Tall (1989) state that generalization is "The process of applying a given argument in a broader context" (p. 38). Another definition explains that generalization is "Lifting the reasoning or communication to a level where the focus is no longer on the cases or situations themselves, but rather on the patterns, procedures, structures, and the relations across and among them" (Kaput, 1999, p. 137). For instance, a student might state that opposite sides of a square are equal in length and this is also valid for a rectangle. Then, through generalization, the student might suggest that a square can be accepted as a specialized case of a rectangle. Another student might notice a specific parallelogram whose sides intersect at $90^{\circ}$ angles. Considering this specific parallelogram, the student might suggest that a parallelogram can also be accepted as a rectangle. However, since the second suggestion cannot be carried on all parallelograms, this suggestion, then, is just an observation, not a generalization. That is, in order to generalize, attending to cases, looking for and identifying commonalities across cases, and extending the reasoning are needed.

Considering the given definitions, generalization can be accepted as both a process in which students engage and a product of students' actions. Researchers who accept generalization as a process state that students perform some kind of behaviours such as comparing figures visually and looking for specific parts of the figure to easily find the rule. These researchers also mention that since the aforementioned behaviours are mental, generalization is an internal construct (Becker \& Rivera, 2005; Radford, 2003). Contrary to this perspective, Chua and Hoyles (2012) mention that generalization is an external construct as students need to find a rule or write in symbols to describe their generalizations. This acceptance emphasizes the connection between the act of generalizing and symbolizing the relationship (Zazkis \& Liljedahl, 2002). Otherwise, although students are able to identify commonalities, hence be able to generalize, they have difficulties in symbolization of their thinking. This difficulty shows the importance of two other concepts: arithmetic generalization, which is generalization without symbolization, and algebraic generalization, which is generalization with symbolization (Radford, 2008). For the purposes of this study, the term generalization used throughout the paper refers to algebraic generalization.

A person who algebraically generalizes can understand what symbols refer to and compute with these symbols. That being said, knowing what symbols refer to or computing with these symbols is not enough for algebraic thinking; justifying why the generalization rule works is also vital. In fact, researchers assert that there is a connection between generalization and justification in a way that these two processes support each other (Blanton \& Kaput, 2011; Rivera \& Becker, 2009). Ellis (2007) explains this connection by stating "engaging in acts of 
justification may be as likely to influence students' abilities to generalize as the other way around" (p. 196). Justification is providing "a convincing argument for why carrying out a series of computations is a valid method for determining the answer of a given computation" (Lo, Grant, \& Flowers, 2008, p. 6). Considering the purposes of this study, the term justification in this study refers to the explanations provided by the pre-service elementary teachers as to why their generalizations are correct.

Lannin (2005) emphasizes that introducing students with algebra as much as earlier would provide opportunities for students to develop their algebraic thinking and understanding. These opportunities can be provided through figural-pattern tasks as students not only observe figures but also discover how these figures are connected to a pattern. Although students find the same rule for a figural-pattern task, they can examine different parts of the task; therefore, figuralpattern tasks are more likely to promote students' algebraic thinking and understanding compared to number-pattern tasks (Becker \& Rivera, 2005). However, in order to change figural-pattern tasks into real opportunities, first of all, teachers need to be aware that these tasks impact students' future success in algebra (Smith, 2003). To pursue students' understanding of the figural-pattern tasks rather than guiding them to write a symbolic rule, teachers need to generalize the tasks in different ways and justify why these ways are correct. In this context, this study aims to understand how pre-service elementary teachers generalize a figural-pattern task and justify their generalizations.

\section{Reasoning Types for Generalization and Justification}

Throughout the generalization process, different kinds of strategies can be used. One of these strategies, recursive strategy, refers to a strategy in which students look for a pattern that exists between two consecutive terms and use this pattern to find the next terms (Lannin, 2005; Zazkis \& Liljedahl, 2002). For example, if a pattern continues by subtracting/adding a constant from the first term, then, students can find near terms by subtracting/adding the constant termby-term repetitively. However, if a difference between two consecutive terms is different, then the recursive strategy does not help students find the subsequent terms. That is, step-by-step drawing or counting the related terms does not help students find the term which is far in the sequence. At this point, explicit strategy or generalizing by extension, as a form of another strategy, is used to identify terms that are far away from the given terms (Kinach, 2014; Lannin, 2005; Mason, 1996).

Furthermore, several types of reasoning can be used under an explicit strategy. The first of them, numerical reasoning, is the most common type of reasoning both teachers and students use. In numerical reasoning, they only focus on numerical cues to develop a rule (Becker \& Rivera, 2006). Another type of reasoning, figural reasoning, focuses on figures of a given pattern to examine the rule of the pattern (Mason, 1996). Students who use figural reasoning focus on different parts of the figures "to connect their symbols and variables to the patterns that generate the figures" (Becker \& Rivera, 2006, p. 466). On the other hand, if both figural and numerical cues are used to develop a rule, then it is called pragmatic reasoning which is the combination of figural and numerical reasoning (Becker \& Rivera, 2006).

Similar to the generalization process, different types of reasoning are also used in the justification process. The first of these types is called inductive reasoning, in which students use specific examples to justify that their rules are correct (Lannin, 2005). Since students justify their rules using particular examples, this reasoning is also called as proof-by-example reasoning. This reasoning is the most common type of reasoning used by elementary students 
(Becker \& Rivera, 2007). Using this type of reasoning is not specific to elementary students; it is also valid for middle school students, even for university students (Harel \& Sowder, 2007). Contrary to the above-explained reasoning, students use characteristics of a specific example to show that these characteristics are common to other terms in some situations. This type of reasoning is called deductive reasoning in which students "see the general in the particular" (Mason, 1996, p. 65). In addition to using specific examples, students can use contextual information of the task to justify their answers as valid (Rivera \& Becker, 2003). For example, in a figural-pattern task, students who use contextual information can decompose the figure into its parts and explain how these parts relate to the rule that they generalized.

\section{Rationale for the Study}

Researchers emphasize the importance of this relationship as nearly all of the reasoning types can be used to generalize a figural-pattern task; however, students need to know the strengths and limitations of the reasoning type that they used (Barbosa \& Vale, 2015; Richardson, Berenson, \& Staley, 2009). Specifically, Dörfler (2008) emphasizes that directing students to one reasoning type may have a "restrictive impact" on students' thinking (p. 153). This explanation puts forward the importance of teachers' role in creating opportunities for students to comprehend the reasoning types for generalization and justification and strengths and limitations of them. However, if teachers themselves do not know these reasoning types, it might not be possible to engage students in such kinds of opportunities. That is, for students to attain necessary opportunities, teachers need to know how different types of reasoning are used throughout generalization and justification. Given the vital importance of teachers' knowledge and the great emphasis on algebra from early grades, irrespective of the fact that they will or will not become elementary teachers, as today's pre-service elementary teachers, their possessing secure knowledge in the reasoning types for generalization and justification is needed to be examined. By this examination, pre-service elementary teachers' difficulties or challenges in generalization and justification process can be documented. These difficulties or challenges can then be overcome during their teacher education programs to help their future students develop a conceptual understanding of algebra.

There have been national studies that investigate pre and in-service teachers' abilities or strategies to generalize (Cilingir \& Yanpar Yelken, 2016; Tanisli \& Kose, 2011; Yesildere \& Akkoc, 2011), as well as pre-service teachers' reasoning types used to generalize and justify linear or non-linear pattern generalization tasks (Tanisli, Kose, \& Camci, 2017). However, as revealed in the previous sentence, the number of studies focusing on both generalization and justification is limited. Furthermore, the only study related to both generalization and justification in the national literature was conducted with pre-service mathematics teachers. Since this study focuses on pre-service elementary teachers, the findings would provide insight into their knowledge of generalization and justification as they were engaged in solving a figural pattern task, and hence would contribute to the related literature. The findings of this study might be compared with those of Tanisli et al. (2017) to help researchers consider the differences or similarities between these two groups of pre-service teachers. In the same way, the findings of this study might help teacher educators consider why pre-service elementary teachers generalize and justify in the way they did. In a similar vein, the findings might offer insight into teacher educators as to how they can provide opportunities that improve pre-service teachers' knowledge related to reasoning types for generalization and justification. In this context, the purpose of this study is to examine pre-service elementary teachers' strategies and reasoning types of generalization used for a figural-pattern task and reasoning types of 
justification provided for their generalizations. To do so, answers were sought for the following research questions:

(1) What kinds of reasoning types for generalization are used by pre-service elementary teachers for a figural-pattern task?

(2) What kinds of reasoning types for justification are provided by pre-service elementary teachers for a figural-pattern task?

\section{Methodology}

\section{Research Design}

To investigate an issue with help of one or more cases which may be a person or a group, the design of case study is used (Creswell, 2007). Furthermore, the main purpose in case studies is not to make statistical generalizations, but to make discoveries about the issue (Yin, 2009). Similar to this emphasis, the main purpose of this study was not to provide statistical conclusions; instead, to understand and gain a sense of pre-service elementary teachers' reasoning types of generalization and justification used in a figural-pattern task solving process. In this respect, a case study design was used to examine reasoning types of generalization and justification used by pre-service elementary teachers, within a specific context which was the Elementary Teacher Education program.

\section{Participants}

The participants consisted of 32 pre-service elementary teachers who were all enrolled in the Elementary Teacher Education program of a university, Turkey. The participants were selected through criterion sampling, which is one of the common forms of purposive sampling (Patton, 2002). Defining a criterion enables researchers to study with participants who might share rich information regarding the aims of a study (Patton, 2002). The criterion was to study with the pre-service teachers who were enrolled in the Method of Mathematics Teaching II course as they learn the topics of patterns both theoretically and pedagogically. At the time of the data collection, all the pre-service teachers enrolled in the researcher's section of the Method of Mathematics Teaching II course volunteered to participate in the study. To provide anonymity, pseudonyms were given to each pre-service teacher such as PST1, PST2, ..., PST32.

\section{Data Collection and Analysis}

To examine pre-service elementary teachers' reasoning types for both generalization and justification, a test including three figural-pattern tasks was prepared by the author by means of the tasks provided in the related literature. While these tasks were designed, it was considered that the pre-service elementary teachers would be able to use different types of reasoning to generalize and justify their rules. These tasks were reviewed by two university faculty members who had expertise in pattern generalization tasks. One of these tasks whose results were presented and discussed in this study was similar to the one in Kirwan's study (2017) and was given in Figure 1. 


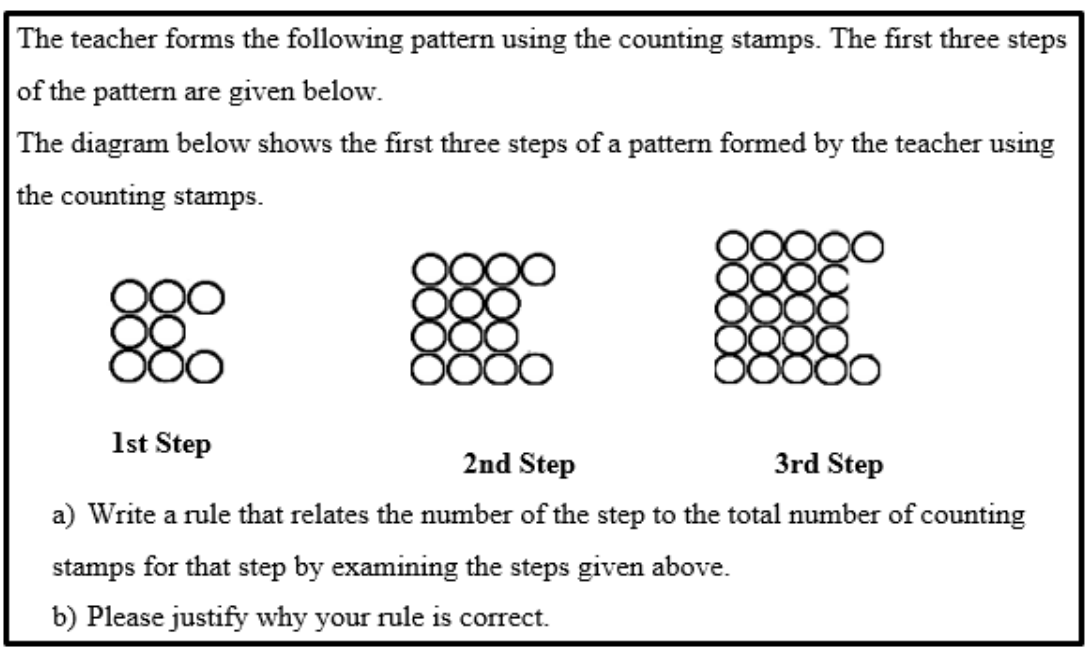

Figure 1. Figural-pattern task

Before administering the task, the pre-service elementary teachers were informed about the topic of patterns, and they worked in pairs to solve different kinds of pattern generalizations tasks during class time of the Method of Mathematics Teaching II course. Throughout the class time, they were not provided with any specific explanations of their reasoning types for generalizations. Then, in the last hour of class time, the test was administered to the pre-service elementary teachers.

Before categorizing the generalizations and justification strategies, and reasoning types used by the pre-service elementary teachers, first of all, it was checked whether or not their rules were correct for the task. Since the pre-service teachers may be able to symbolize the rule in different ways, their rules were accepted as correct if they were equivalent to the rule that was determined before the administration. The determined rule for the pattern was $T=n^{2}+3 n+4$, in which $T$ is the total number of counting stamps, and $\mathrm{n}$ is the step number. Once their rules were determined as correct, these rules were examined for the kinds of the strategy used in the generalizations process. These were as follows: recursive strategy and explicit strategy. Then, the explicit strategy was further separated into figural reasoning, numerical reasoning, and pragmatic reasoning. Finally, the pre-service teachers' reasoning types used in the justification process were categorized as inductive or deductive reasoning.

After the researcher in this study coded the pre-service elementary teachers' generalizations and justification reasoning for the task, a mathematics educator was asked to act as a second coder to ensure reliability. Once the mathematics educator coded a random $25 \%$ of the preservice teachers' strategies and reasoning types used in the generalization and justification process, the inter-rater reliability was calculated by the formula suggested by Miles et al. (2014). As a result, it was found as $91 \%$ and $93 \%$ for reasoning types of generalizations and justification, respectively.

\section{Findings}

Since this paper aims to examine pre-service elementary teachers' reasoning types for generalizations used for a figural-pattern task and justification provided for their generalizations, the findings were presented under two main parts: reasoning types for generalization and reasoning types for justification. For each of these parts, the frequency of 
strategies and reasoning types, and brief quotations taken from the pre-service teachers' papers to exemplify the strategies and reasoning types were presented, respectively.

\section{Reasoning Types for Generalization}

Of the 32 pre-service teachers who participated in this study, 24 pre-service teachers were able to symbolize a rule by using the explicit strategy. While 5 of the 8 pre-service teachers could not even try to see the relationship between the step and the number of stamps in that step using a function-table, the remaining 3 pre-service teachers correctly placed the numbers in the function-table. These three pre-service teachers focused on how the total number of counting stamps change from step to step which was an example of recursive strategy. Specifically, they determined that starting at 8 , the total number of counting stamps increased by $6,8,10,12,14$ and so on, and the total number of counting stamps needed for the fourth, fifth, and sixth steps would be 32, 44, and 58, respectively. However, since they tried to find the rule by just considering the total number of counting stamps, they could not figure out the relationship between the step and the total number of counting stamps in that step and hence could not incorporate their reasoning and reach a rule. For example, one of these pre-service teachers represented the relationship between two consecutive stamps in the given function-table below:

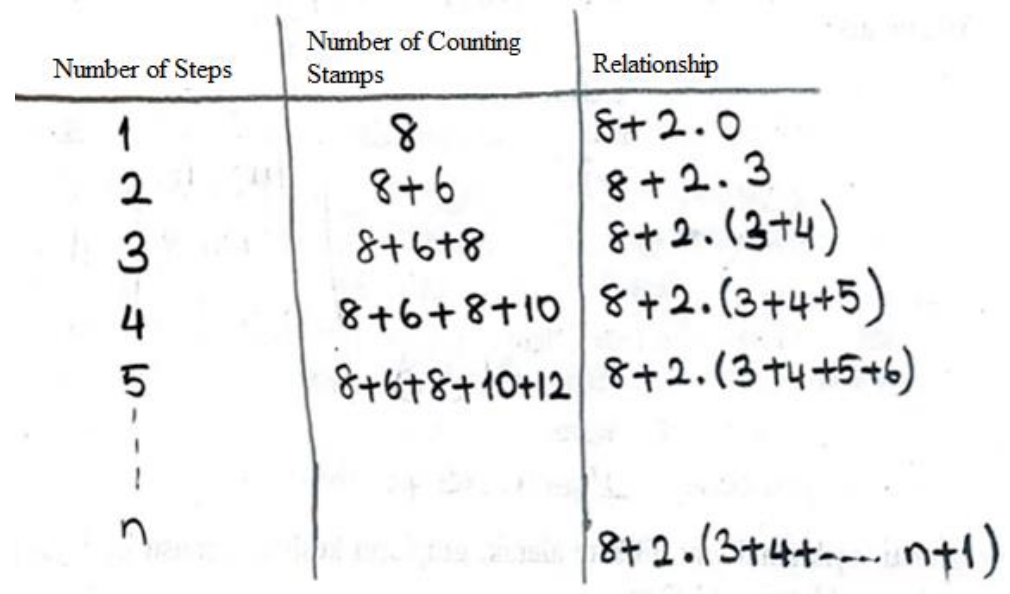

Figure 2. The recursive strategy that PST28 showed in the function-table

As can be understood from the function-table formed by PST28, not only did she discover that the change between two consecutive steps was not constant, but she also recognized how the total number of stamps increased between two consecutive steps. Actually, if she had been able to generalize beyond the specific examples given above, she might have been able to produce the correct rule for the pattern.

The pre-service teachers who provided an explicit and a correct rule for the pattern used different types of reasoning which were numerical reasoning, figural reasoning, and pragmatic reasoning. Table 1 below presents the frequencies of these different reasoning types for the explicit strategy. 
Table 1. Reasoning types and descriptions for explicit strategy developed for the pattern

\begin{tabular}{|c|c|c|c|c|}
\hline $\begin{array}{l}\text { Reasoning } \\
\text { Type }\end{array}$ & Description of Reasoning Type & Numerical Reasoning & $\begin{array}{l}\text { Summary of } \\
\text { Numerical } \\
\text { Reasoning }\end{array}$ & Frequency (n) \\
\hline Numerical & $\begin{array}{l}\text { There is a relationship between the } \\
\text { total number of stamps and the step } \\
\text { number. }\end{array}$ & $(n+1) \times(n+2)+2$ & \multirow{5}{*}{$n^{2}+3 n+4$} & 5 \\
\hline \multirow{3}{*}{ Figural } & $\begin{array}{l}\text { Since the stamps in each step can } \\
\text { be assumed as they make up a full } \\
\text { square array, find the total number } \\
\text { of these stamps by }(n+2)^{2} \text {, and then } \\
\text { subtract the number of stamps } \\
\text { missing in the right column, } n \text {. }\end{array}$ & $(n+2)^{2}-n$ & & 6 \\
\hline & $\begin{array}{l}\text { Since the top and bottom rows have } \\
\text { the same number of stamps, count } \\
\text { stamps either in the top or bottom } \\
\text { row, }(n+2) \text {, and multiply this } \\
\text { number by } 2 \text {, and then add the total } \\
\text { number of stamps make up a } \\
\text { rectangular array in the middle } \\
\text { rows, } \times(n+1) \text {. }\end{array}$ & $2 \times(\mathrm{n}+2)+\mathrm{n} \times(\mathrm{n}+1)$ & & 4 \\
\hline & $\begin{array}{l}\text { Since the stamps on the left } \\
\text { columns make up a rectangular } \\
\text { array, find the total number of these } \\
\text { stamps by }(n+1) \times(n+2) \text {, and then } \\
\text { add the remaining two stamps left } \\
\text { over on the right column, } 2 \text {. }\end{array}$ & $(n+1) \times(n+2)+2$ & & 4 \\
\hline Pragmatic & $\begin{array}{l}\text { Since the stamps in the interior } \\
\text { middle rows make up a full square } \\
\text { array, find the total number of these } \\
\text { stamps by } n^{2} \text {. The first } 7 \text { stamps on } \\
\text { the exterior rows of the first step } \\
\text { can be accepted as constant. Since } \\
\text { the number of stamps increases by } \\
3 \text { each step, multiply by } 3 \text { and add } \\
\text { this number to } 7 \text { to find the number } \\
\text { of stamps on the exterior sides, } \\
7+3(n-1) \text {. }\end{array}$ & $\mathrm{n}^{2}+7+3 \times(\mathrm{n}-1)$ & & 5 \\
\hline
\end{tabular}

The pre-service teachers who employed the numerical reasoning wrote the step number and the total number of stamps in that step in the function-table and focused on the numerical relationship between the columns of this table. Since these pre-service teachers counted the stamps in each step column by column and wrote these numbers in the second column of the table, their thinking initially appeared as figural reasoning. However, it was clear from their explanations that these pre-service teachers just tried to develop a rule to find the total number of stamps using the step number. That is, these pre-service teachers continued to try different rules that would work for the pattern. Actually, the explanation of PST11 given in Figure 3 shows how she came up with the rule, $n^{2}+3 n+4$. 


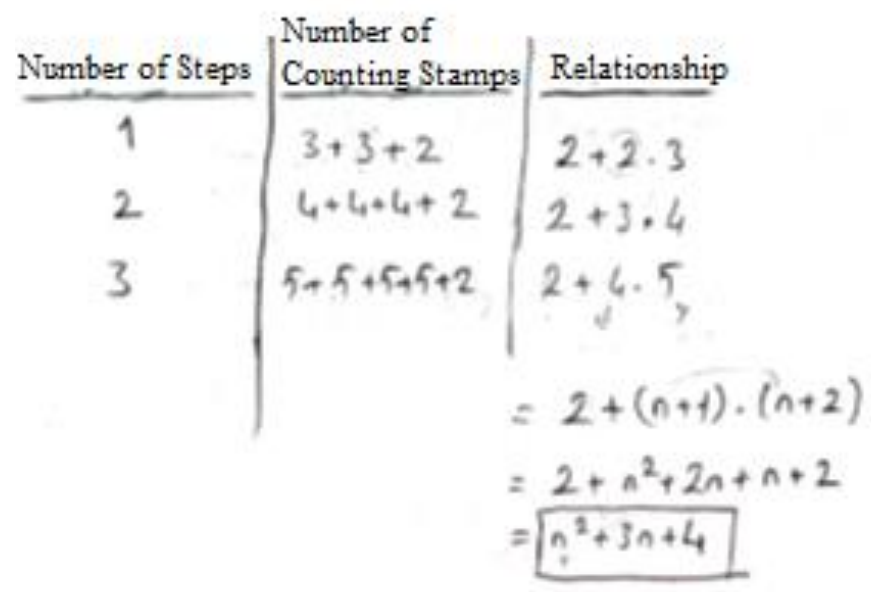

Figure 3. The relationship that PST11 showed in the function-table

In addition to the pre-service teachers who used numerical reasoning, there were also preservice teachers who employed figural reasoning in the generalization process. Although these pre-service teachers developed the same rule for the pattern, they focused on the different parts of the figures and used 3 different strategies. The most frequent strategy was described as if there were full square arrays in each step of the pattern and was used by 6 pre-service teachers. These pre-service teachers recognized that the missing stamps on the right column were equal to the number of the step. Their thinking can be visualized in Figure 4 given below.
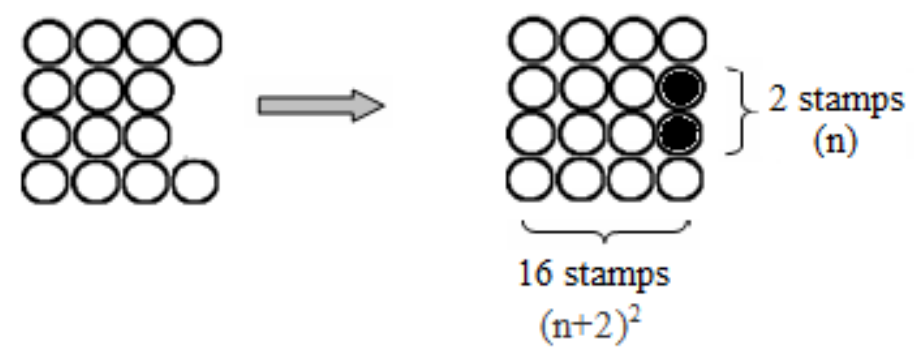

Figure 4. Visualization of the first strategy under the figural reasoning

Similar to this visualization, PST6, one of the above 6 pre-service teachers, visualized and explained her thinking using a function-table in Figure 5 and Figure 6, respectively. "adım" can be translated so that it can be read "step" in the figure.

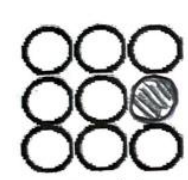

1. Adım

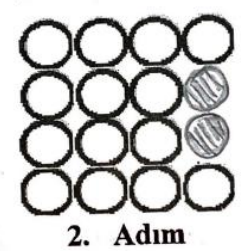

2. Adım

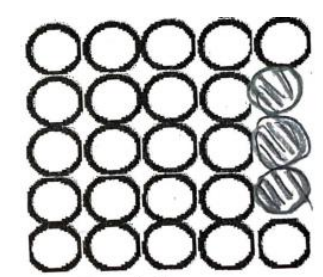

3. Adım

Figure 5. The strategy that PST6 visualized 


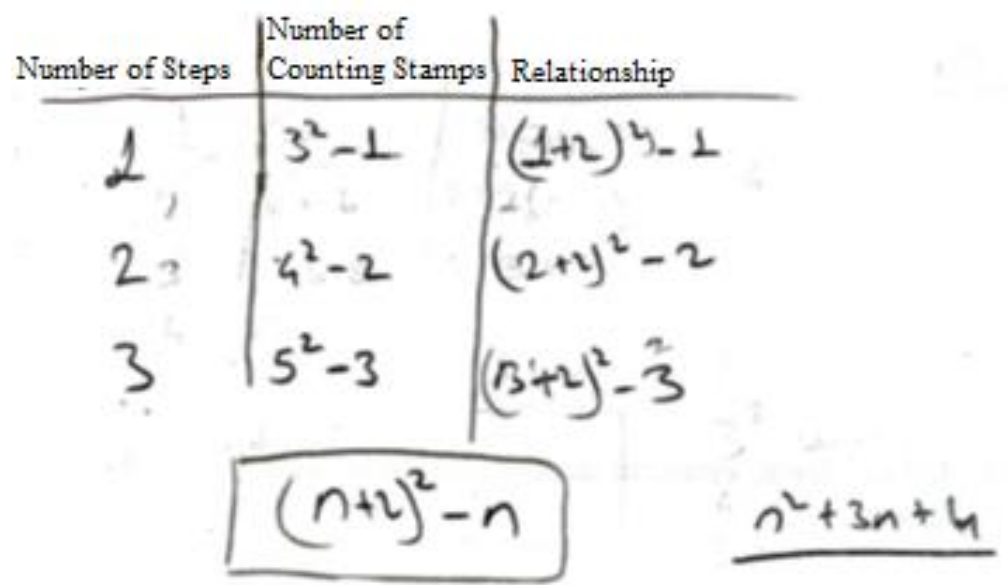

Figure 6. The relationship that PST6 showed in the function-table

In addition to her drawing in Figure 5, the following excerpt obtained from her paper unearths the details of her thinking:

I created squares by imagining that the stamps on the right column were not missing. I saw that there were two more stamps than the number steps on each side at each step ( 3 stamps in the 1 st step, 4 stamps in the 2 nd step, 5 stamps in the 3 rd step). I saw that the number of stamps required to complete the square at each step is equal to the number of steps ( $1 \mathrm{stamp}$ is missing in the 1st step, 2 stamps are missing in the 2nd step, 3 stamps are missing in the 3rd step). Then, I saw that I have to subtract the missing numbers which are equal to the number of steps. So, my rule is $(n+2)^{2}-n$.

Another strategy used by 4 pre-service teachers was described as the figures in each step can be decomposed into three parts: the top row, the middle rectangular array, and the bottom row. The drawing provided in Figure 7 illustrates this strategy.

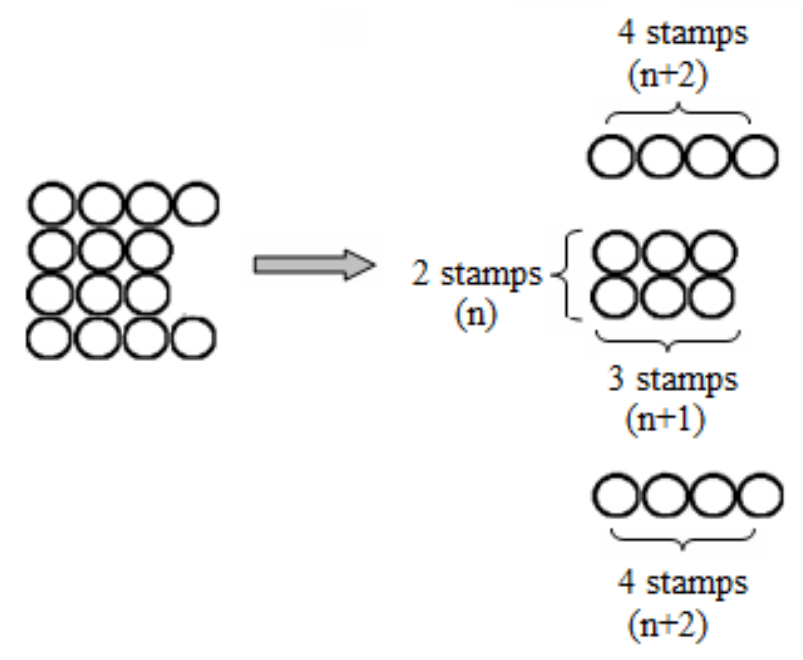

Figure 7. Visualization of the second strategy under the figural reasoning

One of the 4 pre-service teachers who provided the above strategy visualized his strategy in Figure 8 and stated that: 
I did it by decomposing it as the bottom, middle, and top row. There were 3 stamps at the top and bottom rows for the first step, and 4 stamps at the top and bottom rows for the second step. That is to say, the number of stamps on the top row were two more than the number of the steps, $(n+2)$. This is the same for the bottom row. In the middle rows, there was a rectangle whose short side is equal to the number of steps, $\mathrm{n}$, and long side is equal to 1 more than the number of stamps, $(n+1)$. Therefore, there are $n \times(n+1)$ stamps in the middle rows. When I added them all, I reached the rule of $n^{2}+3 n+4$.

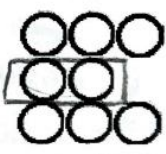

1. Adım

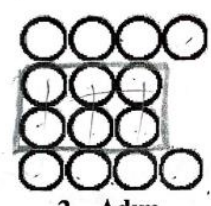

2. Adım

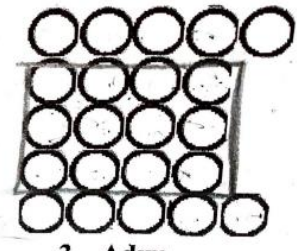

3. Adım

Figure 8. The strategy that PST9 visualized

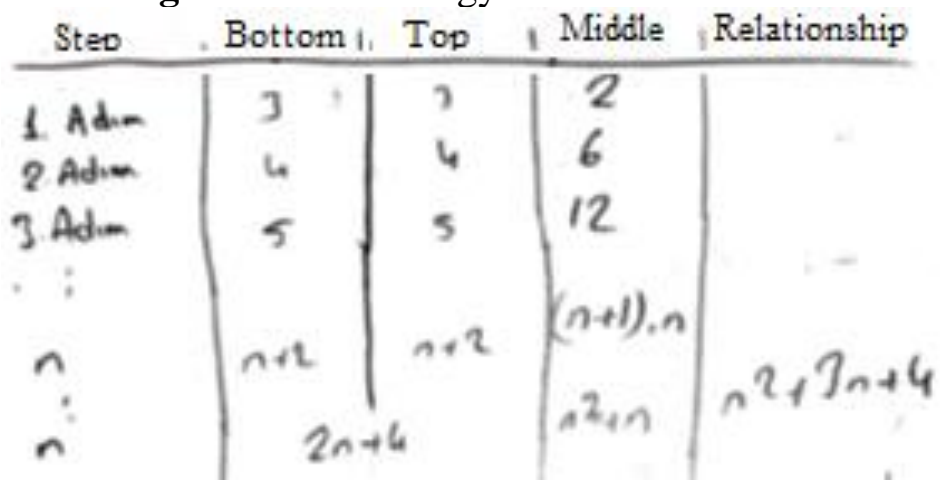

Figure 9. The relationship that PST9 showed in the function-table

There were also 4 other pre-service teachers who employed figural reasoning throughout the generalization process. These pre-service teachers assumed there was a rectangle formed by the stamps on the left columns and two stamps on the right column. This strategy can be visualized in Figure 10.
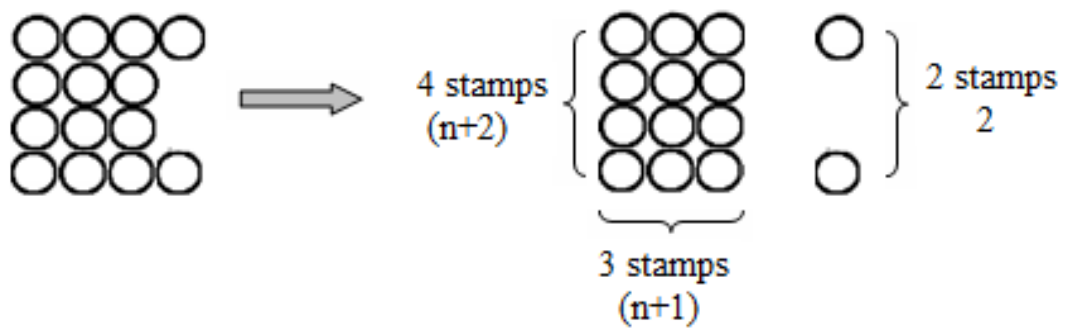

Figure 10. Visualization of the third strategy under the figural reasoning

Similar to Figure 10, Figure 11 and Figure 12, respectively, illustrate this strategy which was visualized and given in a function-table by one of the 4 pre-service teachers who used this strategy. 

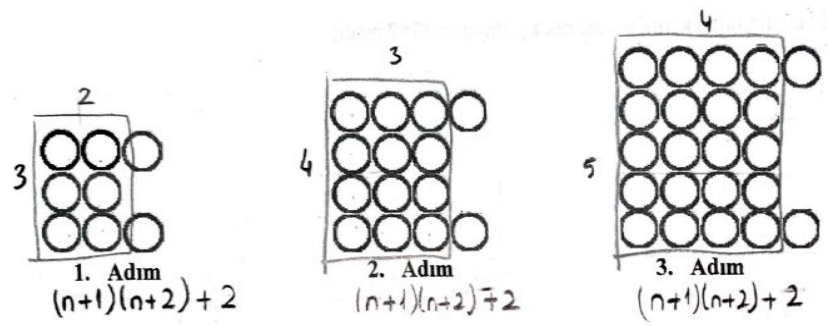

Figure 11. The strategy that PST5 visualized

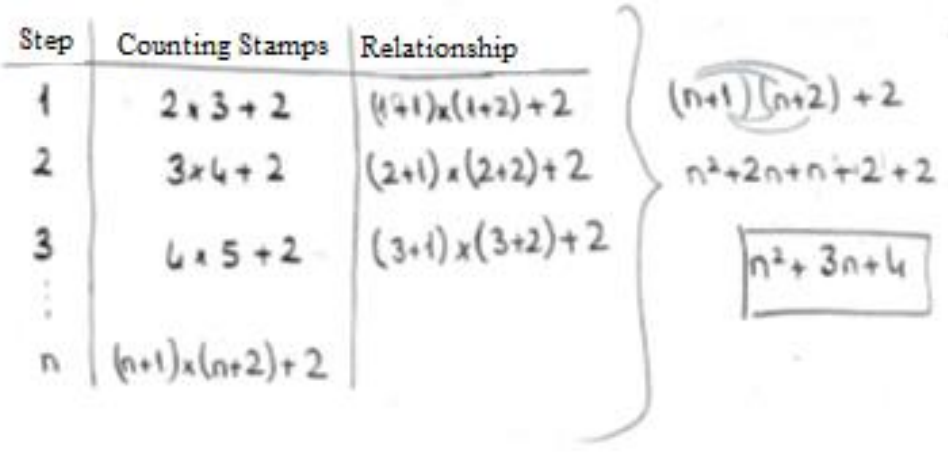

Figure 12. The relationship that PST5 showed in the function-table

As can be understood from the figure and function-table, she was able to correctly determine the variable component, i.e., the growing stamps in the rectangular array, in addition to the constant variable, in this case, two stamps on the right column. Furthermore, the following excerpt from PST5's paper illustrates how she noticed the pattern in the figures:

I formed a rectangle in each step. And apart from these rectangles, there were two stamps left over. The short sides were the step number plus 1, the long sides were the step number plus 2. Since the multiplication of short and long sides gives the area measurement of a rectangle, I found the total number of stamps except for 2 stamps by forming rectangles.

As noted in Table 1, another type of reasoning for the explicit strategy used by 5 of the 24 preservice teachers was pragmatic reasoning. These pre-service teachers decomposed the figures into two parts: interior stamps and exterior stamps, and noticed that the interior stamps make up a full square array. Furthermore, they accepted 7 exterior stamps in the first step as constant and recognized that the number of exterior stamps increases by 3 each step when they placed the number of stamps in the function-table. That is, they articulated both numerical and figural reasoning throughout the generalization process. Figure 13 given below illustrates these preservice teachers' thinking.

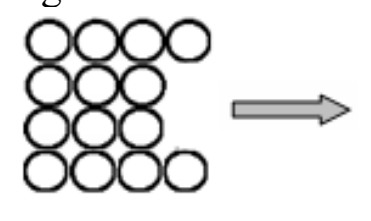

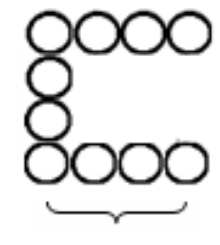

10 stamps

$7+3(\mathrm{n}-1)$

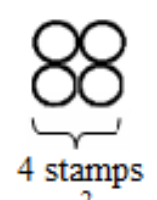

$\mathrm{n}^{2}$

Figure 13. Visualization of the last strategy under the figural reasoning

One of the pre-service teachers who employed the pragmatic reasoning was able to visualize 
her thinking in Figure 14 and Figure 15 given below.

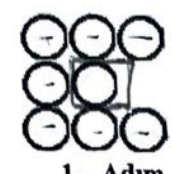

1. Adım
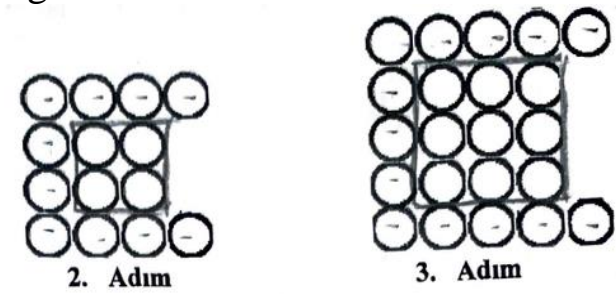

3. Adım

Figure 14. The strategy that PST30 visualized

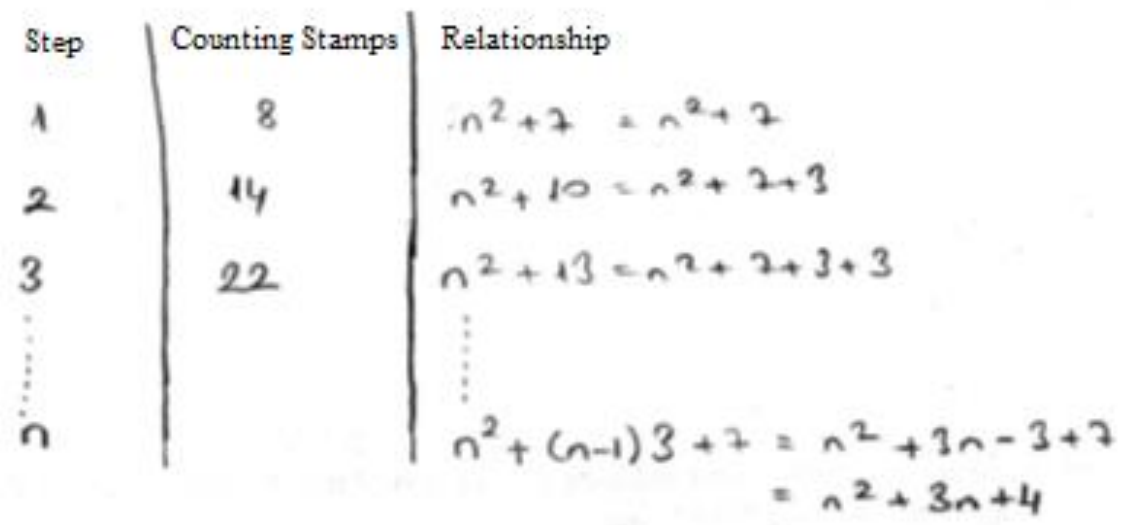

Figure 15. The relationship that PST30 showed in the function-table

As can be understood from the above figures, PST30 considered the visual structure of the stamps; the stamps in the middle interior rows were illustrated by a square array, and mathematical structure of the stamps. Specifically, she explained her thinking for the reasoning that she employed. She stated:

Since I noticed that the stamps in the interior rows form a square, I thought that I would easily find a rule if I decompose the stamps as interior and exterior. Then, I counted the number of stamps on the exterior and saw that it started at 7 in the first step and increased by 3 each step. So, I placed the number of stamps in each step in the table to understand the relationship.

\section{Reasoning Types for Justification}

As mentioned in the reasoning types for the generalization part above, 24 pre-service teachers were able to correctly symbolize the rule for the pattern. Thus, the reasoning types that were offered by these pre-service teachers throughout the justification process were considered. Ultimately, after checking their explanations, it would be fair to state that their reasoning types were generally inductive for the pattern. Deductive reasoning was being offered by a few preservice teachers. The distribution of the pre-service teachers' reasoning types is given in Table 2 .

Table 2. Reasoning types offered for justification for the pattern

\begin{tabular}{ll}
\hline Reasoning Type & Frequency $(\mathrm{n})$ \\
\hline Inductive & 17 \\
Deductive & 7 \\
\hline
\end{tabular}

The pre-service elementary teachers who used inductive reasoning throughout the justification 
process provided particular cases as to why their developed rules were correct. They did not base their rules on visual/contextual structures of the figures given in the steps. Their explanations were similar to such statements "my rule was correct as I could apply this rule to any step number and find the total number of stamps in that step." One example of such an explanation is given below:

Since I substitute the step number in my rule, $\mathrm{n}^{2}+3 n+4$, I am able to correctly find the total number of counting stamps. For example, there are 8 counting stamps in the first step and when I substitute 1 for $n$ in $n^{2}+3 n+4$, it will be equal to 8 . Similar to this, if I substitute 2 for the second step, I will get 14 which is equal to the total number of counting stamps in the second step.

The following is another example of the explanation for inductive reasoning:

I tried the rule that I found for each step and I was able to find the total number of stamps in that step. So the rule that I found is correct.

Contrary to the explanations of the pre-service teachers who justified inductively, the explanations of other pre-service teachers indicated that they focused on the visual/contextual structures of the counting stamps and justified their rules using these structures. The following explanation of PST8 indicates the details about how she justified her rule based on the visual structure of the counting stamps:

If the middle stamps of the last column were not missing, then there would have been full squares in each step of the pattern. If it were like this, then the total number of counting stamps would be $(n+2)^{2}$ which is equal to $n^{2}+4 n+4$. However, I have to subtract the counting stamps I added to make a full square from $n^{2}+4 n+4$, and this number is equal to n. So, the rule will be $n^{2}+3 n+4$.

While each explanation provided by the pre-service teachers who deductively justified their developed rules focused on the visual structures of the counting stamps, one of these explanations was different from the others. All six pre-service teachers tried to show why their developed rules were correct through explanations similar to those given above. However, one pre-service teacher showed how the same rule could be reached by focusing on the different visual structures of the counting stamps. Specifically, the following explanation of PST4 who developed the rule using the first strategy indicates how her focus of visual structures was different from the previously focused ones:

Normally, I had separated the stamps into a rectangle on the left columns and two stamps on the right column. Then, since the area of a rectangle can be found by multiplying the length by the width, the total number of counting stamps that form the rectangle is equal to $(n+1) \times(n+2)$. And if I add two stamps on the right column to $(n+1) \times(n+2)$, it will be $n^{2}+3 n+4$. Actually, if my rule is correct, then I have to be able to find the same rule in a different way. For example, I will try to find the rule by separating the stamps as top, middle, and bottom row. There were $(\mathrm{n}+2)$ stamps at the top, and the number of stamps at the bottom is the same. So, there were $2 \times(\mathrm{n}+2)$ stamps in total. The stamps in middle rows make up a rectangle, so the number of these stamps is equal to $n \times(n+1)$. If I add $2 \times(n+2)$ and $n \times(n+1)$, then I will find the same rule $n^{2}+3 n+4$. Therefore, my rule for the pattern is correct.

As can be understood from the above quotations, the pre-service teachers who offered deductive 
reasoning provided contextual justification for their rules. That is, they did create a relationship between their rules and the visual structure of the pattern. To explore who were the most likely to justify deductively, the distribution of the reasoning types offered for justification according to the reasoning types offered for generalization are depicted in Table 3 below.

Table 3. Distribution of reasoning types offered for justification with regard to reasoning types for generalization

\begin{tabular}{l|l|l}
\hline \multicolumn{1}{c|}{ Reasoning Types Offered for Justification } & Inductive & Deductive \\
Reasoning Types Offered for Generalization & & \\
\hline Numerical & 5 & 0 \\
Figural & 7 & 7 \\
Pragmatic & 5 & 0 \\
\hline
\end{tabular}

As it is clearly seen from Table 3, the pre-service teachers' reasoning types for justification were mostly inductive for all of the reasoning types for generalization. Specifically, the preservice teachers who employed numerical or pragmatic reasoning for generalization offered inductive reasoning to justify their developed rules. Similarly, although half of the pre-service teachers whose reasoning types for generalization were figural for the pattern preferred to use inductive reasoning throughout the justification process, the other half of them justified their rules deductively. That is, the pre-service teachers who articulated figural reasoning were the only ones who used deductive reasoning for justification.

\section{Discussion, Conclusion, and Recommendations}

The purpose of this study was to examine pre-service elementary teachers' reasoning types for generalization used for a figural-pattern task and reasoning types for justification provided for their generalizations. Throughout the generalization process, it was found that the pre-service teachers incorporated two kinds of strategies: recursive and explicit. However, the pre-service teachers who used recursive strategies were not able to produce a rule for the pattern. This finding is similar to that of Yesildere and Akkoc (2011) as they also found that the pre-service mathematics teachers who tried to establish a rule using a recursive strategy had difficulties with generalization. Zazkis and Liljedahl (2002) state that if the change between two consecutive steps is not the same, then developing the rule using the recursive strategy is difficult but not impossible. Considering their statement, the reason for these pre-service teachers' difficulties in developing the rule may result from the non-linear structure of the pattern. Furthermore, these pre-service teachers only tried to find a relationship between the dependent variables, the total number of counting stamps in this study. However, researchers emphasize that to be able to generalize patterns, identifying a relationship between the independent and dependent variables is a must (Harel, 2001; Rivera, 2010; Wilkie, 2014). Therefore, this may as well be the case for these pre-service teachers. To overcome pre-service teachers' difficulties, teacher educators need to include non-linear figural patterns in their courses. Including such kind of patterns may allow pre-service teachers to recognize which strategy is more effective or that the recursive strategy does not always help them develop a rule.

The pre-service teachers who used explicit strategies through generalization were more flexible in their reasoning types. With respect to explicit strategies, the pre-service teachers employed numerical, figural, or pragmatic reasoning to generalize the pattern consistent with the related literature (Tanisli et al., 2017; Tanisli \& Kose, 2011). Most pre/in-service teachers tend to use 
numerical reasoning in generalization. These teachers see figures of a pattern to count for each step and generate a numerical representation of them which is accepted as numerical reasoning (Lannin, 2005; Rivera \& Becker, 2005). That is, they do not return to the original figures to explain how these figures change or how this change relates to the numbers (Markworth, 2012). Unlike the findings of these mentioned studies, among these reasoning types, figural reasoning was the most frequent one and it was used two times more than numerical and pragmatic reasoning types. Taking these perspectives into consideration, the finding that the pre-service teachers in this study preferred to use figural reasoning to generalize extends the related literature.

Researchers also state that pre/in-service teachers who use figural reasoning can easily recognize what stays the same and what changes in figures of a pattern and see figures of a pattern in multiple ways. Being able to see figures in different ways helps these teachers find equivalent rules to their first developed rules (Rivera \& Becker, 2009; Wilkie \& Clarke, 2014). Similar to pre-service mathematics teachers in Tanisli et al.'s study (2017), the pre-service elementary teachers who used figural reasoning in this study focused on the different visual structures of the figures and established the same rule in different ways.

Considering the second purpose of this study, it was found that most of the pre-service elementary teachers used inductive reasoning to justify their rules. Tanisli et al. (2017) also found that pre-service mathematics teachers prefer and try to justify their rules by providing particular cases which is a characteristic of inductive reasoning. Therefore, it can be concluded that similar to pre-service mathematics teachers, pre-service elementary teachers also use inductive reasoning throughout justification process. Rivera and Becker (2009) emphasize that teachers using figural reasoning are better able to justify their developed rules. Researchers also state that these teachers are more likely to establish deductive reasoning for justification than teachers who used numerical reasoning (Markworth, 2012; Warren \& Cooper, 2008; Whitin \& Whitin, 2014). Similar to these statements, deductive reasoning was only employed by the preservice teachers who used figural reasoning to generalize the pattern in this study. Other preservice teachers provided particular cases to justify their rules. However, although the rule worked for the first three steps, it does not mean that it will do so for the other steps. Therefore, it can be concluded that it comes as no surprise that none of the pre-service teachers who generalized numerically gave a deductive justification. However, it is surprising that only half of the pre-service teachers who used figural reasoning gave a deductive justification. To enable pre-service teachers to use deductive reasoning, teacher educators can create an environment in which pre-service teachers share their strategies and reasoning types for generalization. As they share, teacher educators can also ask pre-service teachers to explain their reasoning, so that other pre-service teachers understand their thinking. By means of this discussion, pre-service teachers recognize the advantages and disadvantages of the reasoning types that they used in the generalization and justification process.

The findings of this study might not be representative for other pre-service elementary teachers in Turkey, as the participant pre-service teachers were selected from a single Elementary Teacher Education program. Therefore, a future study may be performed with a bigger sample including pre-service teachers from different regions of Turkey. Furthermore, the pre-service teachers' reasoning types for generalization and justification were examined through their written responses. To provide a more comprehensive view of reasoning types used by preservice elementary teachers to generalize and justify, interviews in addition to their written responses might be incorporated into data collection processes. 


\section{References}

Barbosa, A., \& Vale, I. (2015). Visualization in pattern generalization: Potential and Challenges. Journal of the European Teacher Education Network, 10, 57-70.

Becker, J. R., \& Rivera, F. (2005). Generalization strategies of beginning high school algebra students. In H. Chick \& J. L. Vincent (Eds.), Proceedings of the 29th Conference of the International Group for the Psychology of Mathematics Education (Vol. 4, pp. 121128). Melbourne, Australia: University of Melbourne.

Becker, J. R., \& Rivera, F. (2006). Establishing and justifying algebraic generalization at the sixth grade level. In J. Novotna, H. Moraova, M. Kratka, \& N. Stehlikova (Eds.), Proceedings of the 30th Conference of the International Group for the Psychology of Mathematics Education (Vol. 4, pp. 465-472). Prague, Czech Republic: Charles University.

Becker, J. R., \& Rivera, F. (2007). Factors affecting seventh graders' cognitive perceptions of patterns involving constructive and deconstructive generalization. In J. H. Woo, H. C. Lew, K. S. Park, \& D. Y. Seo (Eds.), Proceedings of the 31st Conference of the International Group for the Psychology of Mathematics Education (Vol. 4, pp. 129136). Seoul, Korea: The Korea Society of Educational Studies in Mathematics.

Blanton, M. L., \& Kaput, J. J. (2011). Functional thinking as a route into algebra in the elementary grades. In J. Cai \& E. Knuth (Eds.), Early algebraization (pp. 5-23). Heidelberg, Germany: Springer Berlin Heidelberg.

Chua, B. L., \& Hoyles, C. (2012). The effect of different pattern formats on secondary two students' ability to generalize. In T. Y. Tso (Ed.), Proceedings of the 36th Conference of the International Group for the Psychology of Mathematics Education (Vol. 2, pp. 155-162). Taipei, Taiwan: PME.

Cilingir, E., \& Yanpar Yelken, T. Y. (2016). Sınıf öğretmenleri adayları ile sınıf öğretmenlerinin şekil örüntüleri konusundaki alan bilgilerinin karşılaştırılması [A Comparison between Pre-service and In-Service Elementary Teachers' Subject Matter Knowledge of Pattern of Figure]. International Journal of Educational Studies in Mathematics, 3(4), 1-16.

Creswell, J. W. (2007). Qualitative inquiry and research design: Choosing among five approaches (2nd Ed.). Thousand Oaks, CA: Sage Publications, Inc.

Dörfler, W. (2008). En route from patterns to algebra: Comments and reflections. ZDM, 40(1), 143-160.

Ellis, A. B. (2007). Connections between generalizing and justifying: Students' reasoning with linear relationships. Journal for Research in Mathematics Education, 38(3), 194-229.

Harel, G. (2001). The development of mathematical induction as a proof scheme: A model for DRN based instruction. In S. Campbell \& R. Zaskis (Eds.), Learning and teaching number theory, journal of mathematical behavior (pp. 185-212). Norwood, NJ: Albex.

Harel, G., \& Tall, D. (1989). The general, the abstract, and the generic in advanced mathematics. For the Learning of Mathematics, 11(1), 38-42.

Harel, G., \& Sowder, L. (2007). Toward comprehensive perspectives on the learning and teaching of proof. In F. K. Lester, Jr. (Ed.), Second handbook of research on mathematics teaching and learning (pp. 805-842). Charlotte, NC: Information Age Publishing.

Kaput, J. (1999). Teaching and learning a new algebra. In E. Fennama \& T. Romberg (Eds.), Mathematics classrooms that promote understanding (pp.133-155). Mahwah, NJ: Lawrence Erlbaum.

Kaput, J. J., Blanton, M. L, \& Moreno, L. (2008). Algebra from the symbolization point of view. In J. J. Kaput, D. W. Carraher, \& M. L. Blanton (Eds.), Algebra in the Early 
Grades (pp. 19-56). Mahwah, NJ: Lawrence Erlbaum Associates/Taylor \& Francis Group.

Kilpatrick, J., \& Izsák, A. (2008). A history of algebra in the school curriculum. In C. E. Greenes \& R. Rubenstein (Eds.), Algebra and Algebraic Thinking in School Mathematics: Seventieth Yearbook (pp. 3-18). Reston, VA: National Council of Teachers of Mathematics.

Kinach, B. M. (2014). Generalizing: The core of algebraic thinking. The Mathematics Teacher, 107(6), 432-439.

Kirwan, J. V. (2017). Using Visualization to Generalize on Quadratic Patterning Tasks. Mathematics Teacher, 110(8), 588-593.

Lannin, J. K. (2005). Generalization and justification: The challenge of introducing algebraic reasoning through patterning activities. Mathematical Thinking and Learning, 7(3), 231-258.

Lannin, J. K., Barker, D., Townsend, B. (2006). Algebraic generalization strategies: Factors influencing student strategy selection. Mathematics Education Research Journal, 18(3), 3-28.

Lee, L. (1996). An initiation into algebraic culture through generalization activities. In N. Bednarz, C. Kieran, \& L. Lee (Eds.), Approaches to Algebra: Perspectives for research and teaching (pp. 65-86). Dordrecht, The Netherlands: Kluwer Academic Publishers.

Lo, J. J., Grant, T. J., \& Flowers, J. (2008). Challenges in deepening prospective teachers' understanding of multiplication through justification. Journal of Mathematics Teacher Education, 11(1), 5-22.

Markworth, K. (2012). Growing patterns: seeing beyond counting. Teaching Children Mathematics, 19(4), 254-262.

Mason, J. (1996). Expressing generality and roots of algebra. In N. Bednarz, C. Kieran, \& L. Lee (Eds.), Approaches to Algebra: Perspectives for research and teaching (pp. 65-86). Dordrecht, The Netherlands: Kluwer Academic Publishers.

Miles, M., Huberman, A., \& Saldaña, J. (2014). Qualitative Data Analysis: A Methods Sourcebook. Thousand Oaks, CA: Sage.

National Council of Teachers of Mathematics (NCTM). (2000). Learning mathematics for a new century (2000 Yearbook). Reston, VA: Author.

Patton, M. Q. (2002). Qualitative evaluation and research methods (3rd Ed.). Thousand Oaks, CA: Sage.

Radford, L. (1996). Some reflections on teaching algebra through generalization. In N. Bednarz, C. Kieran, \& L. Lee (Eds.), Approaches to algebra (pp. 107-111). Dordrecht, The Netherlands: Kluwer.

Radford, L. (2003). Gestures, speech, and the sprouting of signs: A semiotic-cultural approach to students' types of generalization. Mathematical Thinking and Learning, 5(1), 37-70.

Radford, L. (2008). Iconicity and contraction: a semiotic investigation of forms of algebraic generalizations of patterns in different contexts. ZDM, 40(1), 83-96.

Richardson, K., Berenson, S., \& Staley, K. (2009). Prospective elementary teachers use of representation to reason algebraically. Journal of Mathematical Behavior, 28(2-3), 188199.

Rivera, F. D. (2010). Visual templates in pattern generalization activity. Educational Studies in Mathematics, 73(3), 297-328.

Rivera, F. D., \& Becker, J. R. (2003). The effects of numerical and figural cues on the induction processes of preservice elementary teachers. In N. Pateman, B. Dougherty, \& J. Zilliox (Eds.), Proceedings of the 2003 Joint Meeting of PME and PMENA (Vol. 4, pp. 63-70). Honolulu, HI: University of Hawaii. 
Rivera, F. D., \& Becker, J. R. (2005). Figural and numerical modes of generalizing in algebra. Mathematics Teaching in the Middle School, 11(4), 198-203.

Rivera, F. D., \& Becker, J. (2009). Algebraic reasoning through patterns. Mathematics Teaching in the Middle School, 15(4), 212-221.

Smith, E. (2003). Stasis and change: Integrating patterns, functions and algebra throughout the k-12 curriculum. In J. Kilpatrick, G. Martin, \& D. Schifter (Eds.), A Research Companion to Principles and Standards for School Mathematics (pp. 136-150). Reston, VA: National Council of Teachers of Mathematics.

Tanisli, D., \& Kose, N. Y. (2011). Lineer şekil örüntülerine ilişkin genelleme stratejileri: Görsel ve sayısal ipuçlarının etkisi [Generalization Strategies about Linear Figural P Patterns: Effect of Figural and Numerical Clues]. Education and Science, 36(160), 184-198.

Tanisli, D., Kose, N. Y., \& Camci, F. (2017). Matematik öğretmen adaylarının örüntüler bağlamında genelleme ve doğrulama bilgileri [Preservice Mathematics Teachers' Knowledge of Generalization and Justification about Patterns]. Journal of Qualitative Research in Education, 5(3), 195-222.

Warren, E. (2005). Young children's ability to generalize the pattern rule for growing patterns. In H. L. Chick \& J. L. Vincent (Eds.), Proceedings of the 35th Conference of the International Group for the Psychology of Mathematics Education (Vol. 4, pp. 305312). Melbourne: PME.

Warren \& Cooper (2008). Patterns that support early algebraic thinking in elementary school. In C. E. Greenes \& R. Rubenstein (Eds.), Algebra and Algebraic Thinking in School Mathematics (pp. 113-126). Reston, VA: National Council of Teachers of Mathematics.

Whitin, D. J., \& Whitin, P. (2014) Building squares and discovering patterns. Teaching Children Mathematics, 21(4), 210-219.

Wilkie, K. J. (2014). Upper primary school teachers' mathematical knowledge for teaching functional thinking in algebra. Journal of Mathematics Teacher Education, 17(5), 397428.

Wilkie, K. J. \& Clarke, D. M. (2014). Developing students' functional thinking in algebra through different visualizations of a growing pattern's structure. Mathematics Education Research Journal, 28(2), 223-243.

Yesildere, S., \& Akkoc, H. (2011). Matematik oğretmen adaylarinin sekil oruntulerini genelleme surecleri [Pre-Service Mathematics Teachers' Generalization Processes of Visual Patterns]. Pamukkale University Journal of Education, 30(30), 141-153.

Yin, R. K. (2009). Case study research: Design and methods (4th Ed.). Thousand Oaks, CA: Sage Publications, Inc.

Zazkis, R., \& Liljedahl, P. (2002). Generalization of patterns: The tension between algebraic thinking and algebraic notation. Educational Studies in Mathematics, 49(3), 379-402. 